\title{
Penyuluhan Mencuci Tangan sebagai Upaya Mencegah Kecacingan di Panti Asuhan Assomadiyyah Tangerang
}

\author{
Makhabbah Jamilatun ${ }^{1}$ \\ ${ }^{1}$ Poltekkes Kemenkes Banten
}

\begin{tabular}{l} 
Article History \\
\hline Received 13.06.2019 \\
Received in revised form \\
06.09.2019 \\
Accepted 22.09.2019 \\
Available online 28.10 .2019
\end{tabular}

\begin{abstract}
EDUCATION OF HANDWASHING AS AN EFFORT TO PREVENT HELMINTHIASIS AT ASSOMADIYYAH ORPHANAGE TANGERANG. Children are the nation's assets in the future that should receive special attention, such as to protect them from various diseases and infections. Children have a habit of paying less attention to the need for handwashing in everyday life. Diseases that can be caused due to lack of their concern for handwashing, such as helminthiasis. One of the factors that result in high worm infection is the lack of handwashing. Based on this background, it is necessary to do community service, especially in children who are in orphanages in the hope of contributing to prepare early generation of health conscious, so that will have an impact on quality of students' character formation and care for health. The purpose community service activities are children in Assomadiyyah orphanages can understand the importance of hand washing and understand how to perform proper hand washing as well as its application in everyday life. Method of community service activities conducted by providing information and practices related to handwashing. The results of this community service activities is increasing understanding of the children at the Assomadiyyah orphanage about the importance of hand washing and can do it the right way.
\end{abstract}

KEYWORDS: Children, Handwashing, Orphanage. and reproduction in any medium, provided the original work is properly cited. C 2019 Makhabbah Jamilatun.

\section{PENDAHULUAN}

Pembangunan kesehatan pada hakekatnya merupakan bagian integral yang tak terpisahkan dari pembangunan sumber daya manusia. Anak-anak merupakan aset bangsa di masa depan yang harus mendapat perhatian khusus, diantaranya adalah melindungi mereka dari berbagai macam penyakit dan infeksi. Anak-anak mempunyai kebiasaan kurang memperhatikan perlunya cuci tangan dalam kehidupan sehari-hari,

\footnotetext{
${ }^{1}$ Corresponding author: Jurusan Analis Kesehatan Poltekkes Kemenkes Banten, Jl. Dr. Sitanala, Neglasari Kota Tangerang. Email:
} makhabbah.j@gmail.com 
padahal tangan merupakan bagian tubuh yang lembab yang paling sering berkontak dengan agen yang menyebabkan penyakit. Beberapa penyakit yang dapat disebabkan karena kurang pedulinya terhadap kegiatan cuci tangan, diantaranya adalah diare, infeksi saluran pernafasan, infeksi cacingan. Cacingan adalah salah satu jenis penyakit infeksi yang disebabkan oleh adanya cacing di dalam usus manusia. Infeksi kecacingan adalah infeksi yang disebabkan oleh beberapa jenis cacing kelas Nematoda Usus khususnya yang penularannya melalui tanah (Safar, 2010). Beberapa jenis cacing yang sering kali menyerang anak-anak adalah cacing gelang (Ascaris lumbricoides), cacing cambuk (Trichuris trichiura), cacing tambang (Ancylostoma duodenale, Necator americanus) (Irianto, 2013).

Salah satu infeksi yang sering ditemukan pada anak-anak adalah infeksi kecacingan (Mufidah, 2012). Infeksi kecacingan tergolong penyakit neglected disease yaitu infeksi yang kurang diperhatikan dan penyakitnya bersifat kronis tanpa menimbulkan gejala klinis yang jelas dan dampak yang ditimbulkannya baru terlihat dalam jangka panjang seperti kekurangan gizi, gangguan tumbuh kembang dan gangguan kognitif pada anak. Pada umumnya, anak-anak yang terinfeksi cacingan akan mengalami gejala-gejala tertentu seperti lemah, letih, loyo dan lemas (Nadesul, 2006). Hal ini dikarenakan nutrisi penting yang dibutuhkan oleh tubuh diserap oleh cacing, sehingga mengganggu pertumbuhan dan daya tahan tubuh, yang mengakibatkan anak-anak mudah sakit (Mandal, 2008). Menurut Putri dan Yoserizal (2017) dan Notoatmodjo (2012), faktor yang menyebabkan masih tingginya infeksi cacing adalah rendahnya tingkat sanitasi pribadi (perilaku hidup bersih sehat) seperti kebiasaan cuci tangan sebelum makan dan setelah buang air besar (BAB), kebersihan kuku, perilaku jajan di sembarang tempat yang kebersihannya tidak dapat dikontrol, perilaku BAB tidak di WC yang menyebabkan pencemaran tanah dan lingkungan oleh feses yang mengandung telur cacing.

Program pemberantasan penyakit cacing lebih ditingkatkan prioritasnya pada anakanak yang merupakan periode peningkatan perkembangan dan kualitas hidup anak. Penyakit cacingan pada anak-anak dapat mengganggu kemampuan belajarnya. Oleh karena itu pemantauan penyakit cacingan pada anak-anak perlu dilakukan secara kontinyu. Kebersihan tangan yang kurang tentunya berpengaruh dan dapat memberikan kontribusi dalam terjadinya penyakit (Purwandari, Ardiana, \& Wantiyah, 2013). Cara terbaik untuk mencegahnya adalah dengan membiasakan mencuci tangan. Mencuci tangan adalah teknik yang sangat mendasar dalam mencegah dan mengendalikan infeksi, dan dengan mencuci tangan dapat menghilangkan sebagian besar mikroorganisme dan kotoran lain yang ada di kulit (Notoatmodjo, 2012).

Panti asuhan adalah lembaga sosial nirlaba yang menampung, mendidik dan memelihara anak-anak yatim, yatim piatu, dan anak terlantar (Poerwadarminta, 2002). Penanaman kesadaran akan perilaku hidup bersih dan sehat harus dimulai sejak dini tertama sejak anak-anak (Mochtar, 2006). Panti asuhan menjadi sangat strategis untuk pembentukan karakter yang sadar perilaku hidup bersih dan sehat karena terdapat anakanak yang tinggal dan menetap di dalamnya. Salah satu upaya perilaku hidup bersih dan sehat yaitu dengan mencuci tangan. Penelitian yang dilakukan oleh Zubaidi, Hariyanto, dan Ardiyani (2017), menyebutkan bahwa terdapat hubungan yang signifikan antara personal hygiene dengan kejadian penyakit cacingan pada anak, risiko anak terkena infeksi cacing lebih meningkat terutama anak yang memiliki kebiasaan bermain di tanah dan jarang mencuci tangan (Winita, Mulyati, \& Astuty, 2012). Ditambahkan oleh hasil 
penelitian Jodjana dan Majawati (2017), menyebutkan bahwa tidak ditemukannya infeksi cacing dipengaruhi oleh beberapa hal, salah satunya adalah perilaku bersih dan sehat setiap anak.

Berdasarkan observasi yang dilakukan, anak-anak di panti asuhan Assomadiyyah tinggal di dalam komunitas dekat bantaran kali dengan rumah yang cukup sempit. Selain itu, mereka juga memiliki pengetahuan yang rendah tentang kebersihan. Dengan kondisi tersebut, maka perlu dilakukan pengabdian masyarakat khususnya pada anak-anak yang berada di Panti Asuhan Assomadiyyah agar mendapat perhatian tentang perilaku hidup bersih sehat. Pengabdian masyarakat yang dilaksanakan di panti asuhan Assomadiyyyah bertujuan memberikan penyuluhan sehingga anak-anak di panti asuhan Assomadiyyah dapat memahami pentingnya cuci tangan dan memahami cara melakukan cuci tangan yang benar serta mengajak anak-anak untuk melakukan cuci tangan agar menjadi kebiasaan sehari-hari. Pengabdian masyarakat ini diharapkan bisa berkontribusi dalam mempersiapkan generasi dini sadar kesehatan, sehingga akan berdampak pada pembentukan karakter anak didik terutama di panti asuhan Assomadiyyyah, yang berkualitas dan peduli terhadap kesehatan di masyarakat.

\section{METODE PELAKSANAAN}

Kegiatan pengabdian masyarakat dilaksanakan pada hari Senin, tanggal 22 Oktober 2018 di Panti Asuhan Assomadiyyah Kec. Sepatan Kab. Tangerang. Khalayak Sasaran adalah anak-anak yang ada di Panti Asuhan Assomadiyyah Kec. Sepatan Kab. Tangerang. Metode kegiatan yang digunakan dalam kegiatan pengabdian masyarakat ini dilakukan dengan menggunakan beberapa tahapan, yaitu survei kelompok sasaran, identifikasi kebutuhan program, persiapan sarana dan prasarana, pelaksanaan dan evaluasi. Kegiatan dilaksanakan selama satu hari. Sebelum kegiatan penyuluhan, anak-anak di panti asuhan ditanya mengenai apa yang mereka ketahui tentang cuci tangan (pre-test) secara tertulis. Kemudian dilanjutkan penyuluhan cara mencuci tangan yang benar, belajar langkah cuci tangan yang benar dan mempraktikkan cara mencuci tangan dengan benar dengan menggunakan perlengkapan mencuci tangan. Dalam kegiatan praktik, tim pengabdian masyarakat memfasilitasi sarana untuk mencuci tangan dan juga memberikan seperangkat alat cuci tangan pada anak-anak di Panti Asuhan Assomadiyyah yang meliputi sabun cuci tangan serta Lap cuci tangan. Kegiatan diakhiri dengan diskusi serta tanya jawab. Selanjutnya post-test yang dilakukan secara lisan.

\section{HASIL DAN PEMBAHASAN}

Sebelum pelaksanaan kegiatan pengabdian kepada masyarakat, dilakukan beberapa persiapan. Pertama, survei kelompok sasaran dengan melakukan survey lokasi dan berkoordinasi dengan pengasuh panti asuhan Assomadiyyah serta meminta ijin kepada pengasuh panti asuhan. Kedua, identifikasi kebutuhan program terkait pelaksanaan penyuluhan mencuci tangan di Panti Asuhan Assomadiyyah. Ketiga, mempersiapkan sarana dan prasarana yang mendukung program dan materi penyuluhan yang diberikan, peralatan yang digunakan untuk kegiatan praktik, dan menyediakan perlengkapan cuci tangan. 
Pelaksanaan kegiatan pengabdian kepada masyarakat yaitu selama 1 hari pada hari Senin, tanggal 22 Oktober 2018 bertempat di Panti Asuhan Assomadiyyah Kec. Sepatan Kab. Tangerang. Kegiatan ini dihadiri anak-anak dan pengasuh yang ada di Panti Asuhan Assomadiyah.

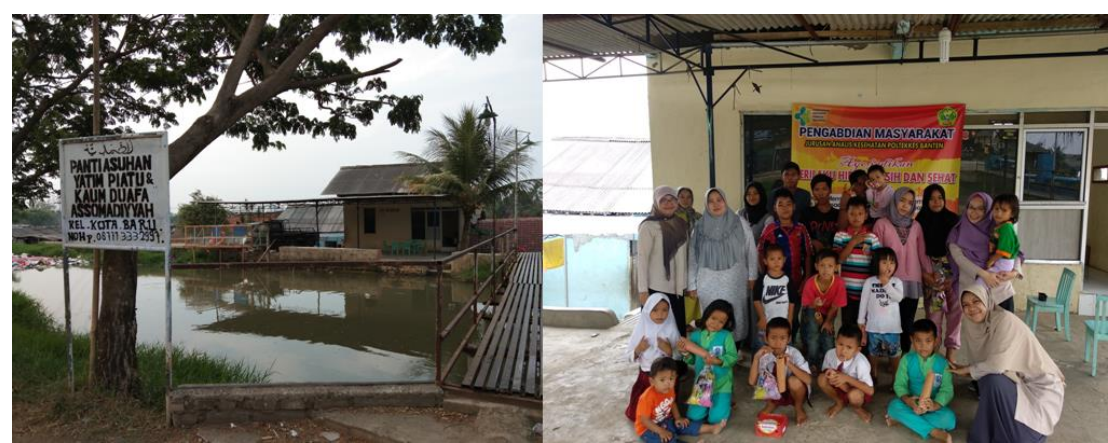

Gambar 1. Lokasi dan Peserta Pengabdian Masyarakat

Sebelum dilaksanakan kegiatan penyuluhan, dilakukan pre-test kepada anak-anak di panti asuhan Assomadiyyah untuk mengetahui pengetahuan dasar mereka mengenai kebiasaan cuci tangan. Pre-test diberikan dalam bentuk kuesioner yang diberikan kepada masing-masing anak untuk diisi sesuai dengan pemahaman mereka. Dalam pengisian kuesioner, anak-anak dipandu oleh tim pengabdian masyarakat.

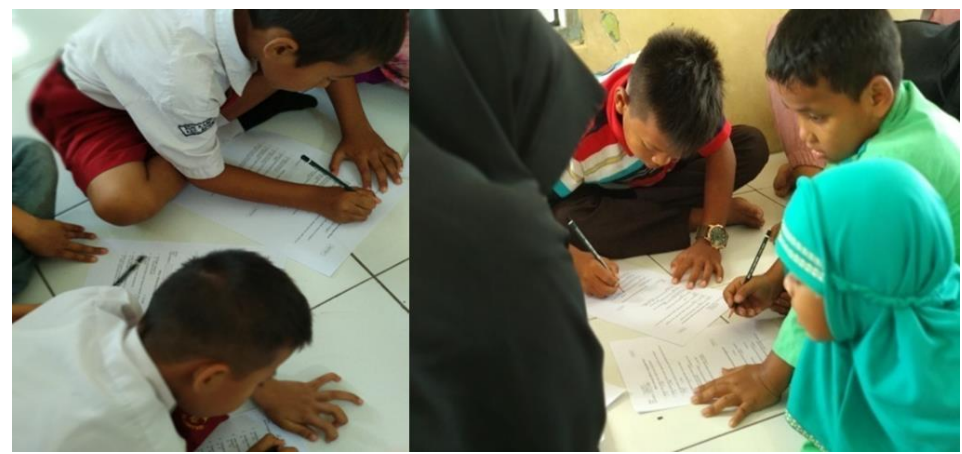

Gambar 2. Pre-Test Sebelum Penyuluhan

Setelah Pre-test selesai dilakukan, kegiatan dilanjutkan dengan penyuluhan. Penyuluhan diawali dengan pembukaan, dilanjutkan perkenalan kemudian penyampaian materi. Penyuluhan tentang langkah-langkah mencuci tangan dilakukan dengan metode presentasi menggunkaan media power point dan video yang ditampilkan melalui layar LCD. Enam gerakan langkah-langkah mencuci tangan sebagai berikut: 1). Tangan dibasahi dan diberi sabun, telapak tangan kiri digosok dengan telapak tangan kanan, 2). Telapak tangan kanan digosok di atas punggung tangan kiri dan sebaliknya, 3). Telapak digosok dengan telapak dan jari saling mengait, 4). Punggung jari diletakkan pada telapak satunya dengan jari saling mengunci, 5). Jempol kanan digosok memutar oleh telapak kiri dan sebaliknya, 6). Jari kiri menguncup gosok memutar ke kanan dan ke kiri pada telapak kanan dan sebaliknya. Setelah materi selesai disampaikan, dilanjutkan dengan diskusi dan tanya jawab dari peserta. Selama penyuluhan, anak-anak di Panti Asuhan Assomadiyyah sangat antusias dan menyimak materi dengan seksama. 


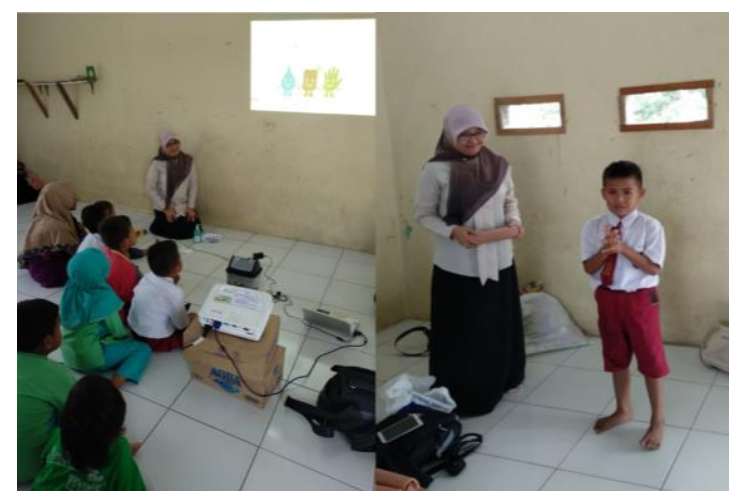

Gambar 3. Penyuluhan Kebiasaan Mencuci Tangan dengan Benar

Untuk menambah pemahaman terhadap materi penyuluhan, maka kegiatan dilanjutkan dengan melakukan praktik mencuci tangan dengan dipandu oleh tim pengabdian masyarakat. Kegiatan praktik dilaksanakan menggunakan sabun dan air mengalir dari kran di samping musholla Panti Asuhan Assomadiyyah. Praktik dilaksanakan oleh masing-masing peserta dengan berjajar berurutan. Masing-masing peserta mempraktikkan setiap langkah cuci tangan dari langkah pertama hingga langkah terakhir, sebanyak enam langkah. Bagi peserta yang mencuci tangan tidak sesuai dengan langkah-langkah yang disebutkan saat penyuluhan, maka peserta diminta untuk mengulangi kembali sehingga peserta paham dan bisa mencuci tangan dengan benar.

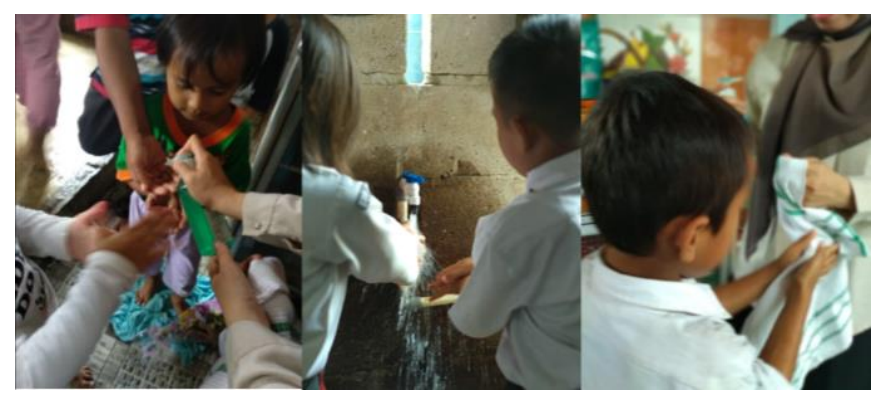

Gambar 4. Praktik Mencuci Tangan

Kegiatan pengabdian masyarakat yang dilaksanakan di Panti Asuhan Assomadiyyah berjalan lancar. Tanggapan pengelola Panti Asuhan Assomadiyyah terhadap kegiatan ini adalah baik sekali karena mereka merasa terbantu dengan adanya kegiatan pengabdian masyarakat seperti ini, terutama dalam upaya penerapan perilaku hidup bersih dan sehat.

\section{SIMPULAN}

Anak-anak di panti asuhan Assomadiyyah menjadi paham akan pentingnya mencuci tangan dan mengerti cara mencuci tangan yang benar. Dengan adanya kegiatan pengabdian kepada masyarakat mengenai penyuluhan kebiasaan mencuci tangan dapat digunakan untuk memasyarakatkan perilaku hidup bersih dan sehat yang merupakan salah satu cara untuk meningkatkan kesadaran masyarakat tentang pemeliharaan dan 
peningkatan derajat kesehatan. Sehingga lingkaran penularan kecacingan dapat dikurangi dan derajat kesehatan anak-anak meningkat.

Berdasarkan pelaksanaan kegiatan pengabdian kepada masyarakat disarankan, mengenai kebiasaan mencuci tangan seharusnya diajarkan sejak dini sehingga anak sudah terbiasa hidup bersih. Untuk mencapai keberhasilan ini, perlu adanya dukungan dan keterlibatan dari pihak pengasuh panti untuk membiasakan mencuci tangan bagi anak asuhnya.

\section{UCAPAN TERIMA KASIH}

Ucapan terima kasih disampaikan kepada UPPM Poltekkes Kemenkes Banten yang sudah mendukung terlaksananya pengabdian kepada masyarakat, serta Panti Asuhan Assomadiyah yang telah bekerjasama dalam kegiatan pengabdian kepada masyarakat sehingga kegiatan dapat berjalan dengan baik.

\section{REFERENSI}

Irianto, K. (2013). Parasitologi medis. Alafbeta: Bandung.

Jodjana, E., \& Majawati, E. S. (2017). Gambaran infeksi cacing Trichuris trichiura pada anak di SDN 01 PG Jakarta Barat. Jurnal Kedokteran Meditek, 23(61), 32-40.

Mandal, B. (2008). Penyakit infeksi. Edisi VI. Jakarta: Erlangga.

Mochtar, S. (2006). Pola asuh orang tua. Jakarta: Rineka Cipta.

Mufidah, F. (2012). Cermat penyakit-penyakit yang rentan diderita anak usia sekolah. Yogyakarta: Flashbooks.

Nadesul. (2006). Kapita selekta kedokteran. Edisi Ketiga. Jakarta: FKUI.

Notoatmodjo, S. (2012). Promosi kesehatan dan perilaku kesehatan. Jakarta: Rineka Cipta.

Putri, M. A., \& Yoserizal, Y. (2017). Perilaku Hidup Bersih dan Sehat (PHBS) Anak di Panti Asuhan Al-akbar Pekanbaru. Jurnal Online Mahasiswa Fakultas Ilmu Sosial dan Ilmu Politik Universitas Riau, 4(2), 1-14.

Purwandari, R., Ardiana, A., \& Wantiyah. (2013). Hubungan antara perilaku mencuci tangan dengan insiden diare pada anak usia sekolah di Kabupaten Jember. Jurnal Keperawatan, 4(2), 122-130.

Safar, R. (2010). Parasitologi kedokteran. Bandung: Yrama Widya.

Poerwadarminta, W. J. S.. (2002). Kamus Besar Bahasa Indonesia. Jakarta: Gramedia Pustaka Utama.

Winita, R., \& Mulyati, \& Astuty, H. (2012). Upaya pemberantasan kecacingan di sekolah dasar. Jurnal Makara, 16(2), 65-71.

Zubaidi, M. M., Hariyanto, T., \& Ardiyani, V. M. (2017). Hubungan personal hygiene (cuci tangan menggunakan sabun) dengan kejadian penyakit cacingan pada anak kelas IVI MI Nahdlatul Wathan (NW) Bimbi Desa Rensing Raya Kec. Sakra Barat Kab. Lombok Timur. Nursing News: Jurnal Ilmiah Keperawatan, 2(3), 360-367. 